\title{
Conflicto obrero y acción guerrillera. La huelga en Mercedes Benz en 1975 y el secuestro de un nazi
}

\author{
Mariano Casco Peebles y María Agustina Leunda
}

Clacso, Conacyt, Universidad de Guadalajara - Universidad de Buenos Aires marianocasco@hotmail.com - agustinaleunda@gmail.com

\section{Introducción}

La relación entre el movimiento obrero y la violencia política en la década del 70 en Argentina ha sido un tema ampliamente debatido en la historiografia y las ciencias sociales. Autores como James (1990), Torre (2004), Izaguirre (2009), Santella (2009), Werner y Aguirre (2009), Basualdo y Lorenz (2012), entre otros, trataron dicha temática en sus trabajos. El presente artículo busca aportar al debate, a partir del estudio del vínculo entre conflictos obreros y acciones guerrilleras. Para ello, analizaremos en sus pormenores la huelga sucedida en Mercedes Benz Argentina (MBA) en octubre de 1975.

La planta se encontraba en el partido de La Matanza a 43 kilómetros de la Capital Federal, hacia mediados de la década del 70 tenía aproximadamente 4.000 operarios y era la principal terminal automotriz productora de utilitarios del país. En ella, al igual que en la mayoría de las empresas automotrices de aquellos años, se vivió una dinámica disputa obrero-patronal con una fuerte inserción de diversas corrientes marxistas y del peronismo combativo.

La huelga de octubre de 1975 se desató con el propósito de exigir un llamado a elecciones a la comisión interna de reclamos (CIR), que se encontraba intervenida por la cúpula sindical hacía meses. Ella duró 22 días, tuvo una amplia participación de las bases y finalizó con un categórico triunfo. Durante la querella, Montoneros -principal agrupamiento en la fábrica- secuestró al gerente de producción como forma de apoyo a los trabajadores y el Ejército Revolucionario del Pueblo (ERP) atentó con explosivos la casa de otro alto ejecutivo de la transnacional.

Consideramos que el estudio de los pormenores de los conflictos, es decir el abordaje del ámbito de la táctica, aporta a la comprensión de 
cuestiones de mayor alcance que se presentan en ellos. En este sentido, la hipótesis planteada es la siguiente: el secuestro de un alto ejecutivo de la empresa por parte de Montoneros en apoyo al conflicto obrero fortaleció la posición de los trabajadores durante la contienda.

La principal herramienta metodológica empleada fue el estudio de caso, se entiende a ésta como un vehículo para explicar, describir o pensar fenómenos mayores. Vale decir que la clave de la selección de Mercedes Benz reside en el potencial de aprendizaje que se pueda dar a partir de él, por lo tanto su utilidad en tanto caso no está en que es un ejemplo "normal" o "típico" o porque se pretende realizar una inferencia estadistica de él (Kroll, 2008). Otra herramienta metodológica a la que se recurrió fue la triangulación de datos y fuentes, es decir, se cruzaron las distintas informaciones que había sobre un tópico específico y gracias a ello se pudo hacer una reconstrucción de los hechos lo más fidedigna posible.

Luego de detallar el caso, en las conclusiones del artículo se buscará reflexionar sobre algunas perspectivas desde las cuales es posible pensar la relación entre el movimiento obrero y la violencia política en general y entre conflictos obreros y acciones guerrilleras en particular.

Este artículo constituye un producto parcial de una investigación sobre la actividad sindical de los trabajadores de MBA. Para llegar a ella hemos recabado información de múltiples fuentes secundarias producidas por distintos actores sociales (prensas comerciales, sindicales y políticas, volantes, investigaciones periodísticas, entre otras) y de entrevistas a ex activistas y delegados de la fábrica.

\section{Contexto de la huelga}

Caracterizamos el período iniciado con los hechos sucedidos en la ciudad de Córdoba el 29 de mayo de 1969 y finalizado con la instauración de la última dictadura militar como uno signado por una alta conflictividad social en general y obrera en particular (Balvé et al., 2007; Brennan, 1996; Izaguirre, 2009; James, 1990; Torre, 2004; Werner y Aguirre, 2009). Los diversos "azos", las huelgas obreras y movilizaciones estudiantiles, la vuelta del peronismo al poder luego de casi dos décadas, el desarrollo de organizaciones político-militares, las jornadas de junio y julio de 1975, la lucha contra el plan Mondelli y la virulenta respuesta represiva tanto estatal como paraestatal son ejemplos de ello.

Durante ese periodo los trabajadores de IKA-Renault, Fiat, Citroën, Chrysler, Peugeot, Ford, General Motors y Mercedes Benz fueron punta de lanza de los distintos levantamientos de masas que existieron, tales como el Cordobazo, el Viborazo, y las luchas contra el Rodrigazo y el 
Plan Mondelli. También sufrieron de manera privilegiada la represión desatada en ese entonces.

El año en que sucede el enfrentamiento, 1975, fue particularmente conflictivo. En junio, el flamante ministro de economía, Celestino Rodrigo, implementó una serie de medidas económicas que tuvieron como consecuencia directa un proceso inflacionario que pulverizó en pocos dias el salario del conjunto de los trabajadores y las capas medias. Como respuesta a dicha situación los trabajadores llevaron a cabo numerosas huelgas y movilizaciones que culminaron en una huelga general (Cotarelo y Fernández, 1998).

Vale destacar que dicho movimiento tuvo como epicentro la Capital Federal y sus alrededores, en donde fueron protagónicas las coordinadoras interfabriles que nucleaban a los organismos de base de los trabajadores (principalmente comisiones internas y cuerpos de delegados) (Löbbe, 2006). Dichos organismos sindicales eran dirigidos por agrupamientos opuestos a las direcciones oficiales de los sindicatos (las que también tuvieron un papel inestimable en las movilizaciones) y, a diferencia de estos últimos, eran independientes del gobierno de turno.

Otro dato de relevancia que caracterizó dicho año fue el aumento de la represión a las bases sindicales por parte de la Alianza Anticomunista Argentina (Triple A), de agrupamientos paramilitares similares y de las fuerzas represivas del Estado. El operativo a inicios de 1975 contra los trabajadores de Villa Constitución sirve de ejemplo (Santella, 2009).

\section{El enfrentamiento en Mercedes Benz}

En enero de 1974 las altas temperaturas sufridas en la terminal automotriz de González Catán generó una ocupación parcial de la planta exigiendo la refrigeración de los pabellones. De esta lucha surgieron nuevos referentes sindicales independientes de la cúpula sindical, los cuales ganaron la elección a la comisión interna que se realizó unas semanas después. Dicho espacio gremial estuvo hegemonizado por la Juventud Trabajadora Peronista (JTP) vinculada a Montoneros.

Pero esa comisión no estuvo mucho tiempo al frente de la fábrica debido a que la patronal y la dirección sindical obligaron mediante "amenazas y aprietes" a que renuncie la mayoria de los integrantes de la flamante organización gremial. Maniobra que fue completada por el dirigente del Sindicato de Mecánicos y Afines del Transporte Automotor (SMATA) José Rodríguez dos meses después cuando impugnó la CIR

1."Mercedes Benz: Triunfo de los trabajadores contra el monopolio y la burocracia del SMATA", El Auténtico, 12 de noviembre de 1975, p. 4. 
(aduciendo falta de integrantes) y designó dos interventores, Rubén Darío Aguiar y Juan Carlos Selles.

La anómala situación gremial fue lo que provocó un estallido contra la intervención sucedido en octubre de 1975, con el que se inició el paro de 22 días en Mercedes Benz.

El 8 de octubre, en una asamblea realizada en la puerta de la salita de los interventores, se declaró una huelga donde se eligieron a mano alzada a los representantes de los trabajadores. Allí se conformó la comisión interna provisoria del "grupo de los 9" y un cuerpo de delegados provisorio de 60 integrantes organizado por sección de trabajo. Las reivindicaciones principales de los trabajadores eran el fin de la intervención y el llamado a elecciones de la CIR, y la aplicación del reajuste cuatrimestral de salarios de acuerdo con el alza del costo de vida que fijó el convenio del SMATA.

Al día siguiente, los interventores se dirigieron a la empresa con un grupo de hombres con armas de fuego. Aguiar manifestó que el SMATA no reconocía a la comisión interna provisoria, que "levantaba" la intervención y que designaría un delegado normalizador. Los obreros respondieron repudiando a los interventores, atacando los dos autos en que habian llegado el grupo de civiles armados y declarando indeterminado al paro. Un trabajador entrevistado sostuvo que durante la huida de los matones lograron quedarse con buena parte del armamento que llevaban. ${ }^{3}$

El 11 de octubre el Ministerio de Trabajo declaró ilegal la huelga amparándose en la "tregua" entre patronal y trabajadores establecida unos dias antes por el ministro Carlos Ruckauf. Esta "tregua" no permitía paros sin la aprobación de las dirigencias sindicales, ni despidos "injustificados" por parte de los empresarios. El lunes 13 fueron al sindicato unos 50 trabajadores de MBA para reclamar apoyo, encontrando una negativa como respuesta.

En la mañana del martes 14, la gerencia de MBA despidió 117 activistas incluyendo a la recientemente conformada comisión interna y envió intimaciones a otros 400 trabajadores más. La respuesta fue inmediata, coreando "los 4.000 adentro, los 4.000 afuera" resolvieron salir de la planta y tener una asamblea en la puerta de la fábrica para que todos pudieran participar. La decisión de la patronal radicalizó la disputa y le brindó mayor visibilidad. Como respuesta a los despidos comenzó una nueva ofensiva por parte de los obreros movilizados.

Con el endurecimiento de la contienda el apoyo hacia la movilización

2. De los nueve integrantes, dos eran de la JTP y uno era del Partido Revolucionario de los Trabajadores (PRT), los demás eran independientes.

3. Entrevista realizada a "Andrés" el 21 de septiembre de 2015. 
en Mercedes Benz se fue extendiendo hacia otros sectores sociales. En Cañuelas (localidad cercana a la fábrica) los familiares de los obreros organizaron una asamblea de "autoconvocados" encabezada por María Luján, ${ }^{4}$ desde la cual llevaron adelante un multitudinario acto el miércoles 22 en el centro de la aludida ciudad. El evento, al que asistieron más de 2.000 personas, fue acompañado por un paro de comerciantes comenzado al mediodía.

El intendente de Cañuelas y el gobernador bonaerense Victorio Calabró -dirigente de la Unión Obrera Metalúrgica (UOM)- también ofrecieron su apoyo. El senador por el FREJULI (Frente Justicialista de Liberación) e integrante de la UOM, Afrio Pennisi, dio su solidaridad, como así también lo hicieron los referentes del radicalismo Ricardo Balbin y Oscar Alende.

Las comisiones internas de las empresas metalúrgicas Santa Rosa, FAPESA y MAN, de la jabonera Jabón Federal, y de Indiel apoyaron a los huelguistas, siendo las cuatro primeras integrantes de la Coordinadora Interfabril de La Matanza. También prestaron su apoyo representantes de las empresas Grafa, Monofor, Termoeléctrica y personal del Teatro Avenida, quienes dieron donaciones que fueron desde los 400 mil hasta los dos millones de pesos. Y "el jueves 16 se efectuaron paros de $15 \mathrm{mi}$ nutos por turno en la planta Safrar-Peugeot, en adhesión a los obreros en conflicto de Mercedes Benz". ${ }^{5}$

En la misma semana de los 117 despidos un comando del ERP, brazo armado del PRT, "atentó con explosivos contra la vivienda de un ejecutivo de Mercedes Benz". ${ }^{6}$ Y el viernes 24 de octubre, "los Pelotones Montoneros de Combate Belaustegui y Juan 'Pacho' Sanandrea detuvieron al ingeniero alemán Franz Metz, gerente de producción y accionista de la empresa automotriz Mercedes Benz", ${ }^{7}$ reclamando la reincorporación de los despedidos, el cumplimiento de la totalidad del pliego de reivindicaciones exigidas por los trabajadores y un rescate monetario destinado al beneficio del agrupamiento político-militar. También pidieron la publicación de solicitadas en ocho grandes periódicos: "En Francia (Le Monde), Italia (Corriere dela Sera), Inglaterra (The Guardian), Estados Unidos (Washintong Post), México (Excelsior), Venezuela (Punto), Perú (Correo) y Alemania (Suddeutsche Zeitung)" (Tomuschat, 2003).

Aunque la organización que ejecutó el secuestro lo desconocía, Metz

4. Militante de la Juventud Peronista (JP), esposa de Esteban Reimer, quien era parte de la JTP y referente sindical de MBA desaparecido en enero de 1977.

5. "Cumple 13 dias la huelga en Mercedes Benz", El Cronista, 22 de octubre de 1975, p. 8.

6. "Crónica de la guerra revolucionaria”, Estrella Roja, 17 de octubre de 1975, p. 17.

7. “Crónica de la resistencia”, Evita Montonera, noviembre de 1975, p. 27. 
no sólo era un "experto en la represión de los conflictos laborales en la fábrica" ${ }^{8}$ sino que también fue integrante del Partido Nacional Socialista Alemán bajo el mando de Hitler y con la desnazificación de Alemania se exilió clandestinamente en Argentina. No fue el único, la llegada de Mercedes Benz a Argentina en 1951 sirvió para que numerosos personajes con un pasado nazi pudieran ocultarse. Eichmann, conocido mundialmente por sus crimenes de guerra, trabajaba de electricista en la empresa al momento de su detención por un comando israelí en 1957 (Weber, 2005). De hecho, los trabajadores de la empresa se referian coloquialmente hacia los alemanes que laboraban ahí como "los nazis". ${ }^{9}$ Y en particular a Metz "le decian Panzer. Viste, como los tanques alemanes, era grandote gordo, colorado". ${ }^{10}$

El secuestro estuvo enmarcado en una situación de amenazas a los directivos de la empresa por parte de dos organizaciones políticomilitares (OPM), el ERP y Montoneros. En un informe elaborado por Tomuschat-académico que elaboró un informe para desligar a la empresa alemana de su responsabilidad en la desaparición de los operarios de la fábrica, que tuvo acceso a los protocolos del directorio de MBA- se afirma que "aparecian volantes en los que miembros de la dirección específicamente mencionados o la dirección en general era amenazados de muerte", y luego agrega:

Por ejemplo, en un boletín sin fecha del grupo "Montoneros" aparecía la anotación manuscrita: "Próximo sos vos, Knuth. Ojo". O la "Advertencia", también sin fecha, del Ejército Revolucionario del Pueblo, en la que fueron amenazadas varias personas del plano gerencial medio de MBA. (Tomuschat, 2003)

El lunes 27, la empresa empezó a ceder, envió telegramas de reincorporación a algunos trabajadores, abrió las puertas de la fábrica para que la asamblea se realice adentro y el sindicato repartió un volante donde se comunicaba la obtención de un aumento de sueldo.

Al otro día, en la asamblea del martes 28 , miles de trabajadores decidieron ir al Ministerio de Trabajo en Capital Federal para demandar una audiencia, pero no fueron atendidos. Después de dirigirse al mismo, los obreros fueron al Canal 11 de TV buscando que su reclamo tenga mayor visibilidad y designaron para hablar frente a las cámaras a Hugo Crosatto un integrante del "grupo de los 9" y militante del PRT. ${ }^{11}$

8. "Crónica de la resistencia", Evita Montonera, noviembre de 1975, p. 27.

9. Entrevista realizada a "Juan" el 20 de julio de 2015.

10. Ídem.

11.La militancia partidaria del mencionado referente del "grupo de los 9" era solamente 
Producto de la falta de respuestas por parte del Ministerio de Trabajo, el miércoles 29 le apuntaron directamente a la empresa, la cual se encontraba en mayores aprietos (la planta sin producir hacía más de veinte días, un gerente secuestrado, trabajadores cada vez más radicalizados y sin perspectivas de que cedan en sus reivindicaciones). Más de 3.000 trabajadores de Mercedes Benz se movilizaron por sus propios medios hasta las oficinas centrales de la firma en Capital Federal y aguardaron alli los resultados de las tratativas obrero-patronales.

Concluidas las negociaciones, los 9 integrantes de la CIR anunciaron la amplia victoria obtenida, escuchándose de fondo "mamadera, mamadera, nadie quedó afuera". La empresa había aceptado pagar los salarios caídos durante la disputa, reincorporar a la totalidad del personal despedido, reconocer al "grupo de los 9" como únicos representantes de los trabajadores mecánicos, el pago de una gratificación especial del $40 \%$ y la promesa de no efectuar represalias. Un trabajador recuerda que

una cosa que la patronal no la perdonó nunca, y los jefes y los gerentes tampoco, que fue algo sumamente emocionante, fue que cuando nosotros triunfamos y entramos a la fábrica dimos una "vuelta olimpica", entramos todos en un turno, los 4.000 y se dio toda una vuelta olimpica a la fábrica y yo tengo así en la memoria la cara de los jefes y de los capataces con un odio de clase muy grande, yo creo que eso los tipos no nos lo perdonaron nunca. ${ }^{12}$

El día 31 de octubre MBA sacó una solicitada en el diario Clarín informando la finalización de la contienda, concluyendo, de esta manera, la huelga que se había iniciado semanas antes.

El 23 de diciembre Montoneros recibió el dinero y al día siguiente dejó en libertad al gerente de producción secuestrado. Luego de su liberación, Metz se volvió inmediatamente a Alemania. Mientras la central alemana declaró el envío de 7,5 millones de dólares y los gerentes de MBA, Pedro De Elías y Rubén Cueva, afirmaron que pagaron 4 millones, la organización dirigida por Firmenich sostuvo que solo recibieron dos millones de dólares (Weber, 2005). La solicitada en The Guardian aparecida el 24 de diciembre de 1975 versaba:

La razón de la detención de un empleado de la compañía Mercedes Benz está relacionado con un conflicto laboral que dio lugar al despido de más de 100 trabajadores, y por la ne-

conocida por los activistas cercanos a él.

12. Entrevista realizada a "Juan" el 20 de julio de 2015. 
gativa de la empresa para aceptar justos reclamos de aumento salarial. (Tomuschat, 2003)

El triunfo obrero modificó la situación al interior de la firma. La dirigencia del SMATA sufrió una derrota y como respuesta sacó una solicitada en los periódicos Clarín, La Nación y El Cronista Comercial firmada el 4 de noviembre en la que acusó a la flamante comisión interna de ser "prohijada por la subversión" ${ }^{13}$ y en la cual exigian una sanción a la empresa por haber negociado a espaldas del sindicato y del gobierno.

Por su parte, "el grupo de los 9", una vez reconocido por la empresa, logró significativas reivindicaciones de los trabajadores como la recategorización de tareas, lo que redundó en un aumento del salario para numerosos obreros. El comité de lucha ${ }^{14}$ creó una revista denominada Engranaje en la cual los trabajadores escribian sobre lo que sucedía en la empresa. Durante esos meses el desarrollo sindical de los mecánicos de MBA alcanzó tal nivel que una de las empresas más poderosas del mundo definió en su reunión de directorio del 8 de enero de 1976 que había que "empeñarse en primer lugar en no dejar que surjan los conflictos" (Tomuschat, 2003).

El nivel de organización y movilización de los trabajadores de MBA recién se redujo luego del aumento de la represión durante la dictadura militar (1976-1983). Entre los años 1976 y 1977 quince obreros de la empresa desaparecieron.

\section{Las organizaciones marxistas y del peronismo combativo en Mercedes Benz}

Un hecho inseparable de la organización alcanzada por los trabajadores de Mercedes Benz en el paro es el grado de inserción que obtuvieron las corrientes marxistas y del peronismo combativo dentro de la fábrica. La triangulación de las fuentes permite advertir que, en 1975, poseian militancia la JTP, el PRT, el Partido Comunista (PC), el Partido Socialista de los Trabajadores (PST), el Peronismo de Base (PB), el Partido Comunista Revolucionario (PCR) y el Grupo Obrero Revolucionario (GOR). Por ello, en este apartado mencionaremos brevemente tanto la inserción de cada agrupación política al momento de la disputa como el balance que hicieron de ella una vez finalizada. Para eso nos centramos en los

13. José Rodríguez, "SMATA: A la opinión pública del país", Clarín, 6 de noviembre de 1975 , p. 16.

14. El comité de lucha era un espacio de organización que reunía al activismo de Mercedes Benz. Durante la dictadura militar-dificultados los otros espacios sindicales más "públicos"- el comité se encargó de organizar distintos ataques contra la empresa. 
artículos publicados en sus prensas partidarias, dado que expresan la posición pública de la organización. ${ }^{15}$

La organización inserta más importante fue la JTP. En esto concuerdan -sin excepción- todos los entrevistados. Ella encabezó el proceso electoral de 1974 que le ganó la comisión interna a José Rodríguez y tuvo más integrantes dentro del "grupo de los 9". El triunfo que implicó el secuestro de Metz fortaleció aún más su posición predominante dentro de la planta de González Catán. Además, había trabajadores de la empresa que desarrollaban su politica en otros espacios de base de Montoneros, como la Juventud Peronista de Cañuelas, lugar donde vivian buena parte de los operarios de Mercedes Benz.

Montoneros, una vez finalizado el conflicto, en el número 9 de Evita Montonera argumentó que la lucha "legal" (refiriéndose a la huelga y la movilización) por sí sola no hubiera podido romper la alianza entre patrones, burocracia y Estado, y que el enfrentamiento hubiera caído en un callejón sin salida como lo hizo el de Villa Constitución. En este sentido, el secuestro rompió la "santa alianza" y permitió el triunfo obrero. ${ }^{16}$

Por su parte, el PRT tuvo varias células que funcionaron al menos desde 1971 hasta 1977 con presencia en distintas secciones de la terminal y también un destacado integrante dentro de la comisión interna provisoria que encabezó la medida de fuerza.

En el número 190 de El Combatiente la organización destacó que "la capacidad de organización demostrada por los trabajadores a lo largo del conflicto se erigió en una herramienta decisiva para alcanzar la victoria". ${ }^{17}$ A lo que le sumaron como variable de importancia la solidaridad de los obreros de la zona y la unidad de los trabajadores de MBA. Por otra parte, para el PRT, el secuestro de Metz "vino a robustecer y dar nuevas perspectivas al combate proletario". ${ }^{18}$

Si bien el PC tuvo una importancia menor en el convulsionado 1975 frente al desarrollo de la JTP y del PRT, era la agrupación con más antigüedad dentro de la fábrica dado que detentaba cierta militancia, por lo menos, desde fines de la década del 60.

Su periódico Nuestra Palabra no dedicó una nota individual al triunfo

15. En aquel momento Montoneros editaba una revista producida por su conducción -Evita Montonera-y un periódico de tirada masiva-El Auténtico-. Como se encuentran algunas diferencias en el balance que ambas hacen de la huelga, nos decidimos por tomar Evita Montonera dado que expresa de manera más acabada la mirada oficial de la organización. Por otro lado, no se tuvo acceso a ningún material de PB ni del GOR que haga referencia a la contienda que estamos estudiando.

16. "Mercedes Benz: Derrota de patrones y burócratas", Evita Montonera, noviembre de 1975 , p. 32.

17. “Triunfo obrero en Mercedes Benz", El Combatiente, 5 de noviembre de 1975, p.15. 18. Ídem. 
de los trabajadores de Mercedes Benz. Dentro del artículo titulado "El SMATA de las bases" manifestaron su "alegría" por la victoria y destacaron tanto el "carácter abierto y prolongado" de la querella, como la "unidad y combatividad del personal". ${ }^{19}$

El Partido Socialista de los Trabajadores (PST), hasta 1972 Partido Revolucionario de los Trabajadores-La Verdad, intervenía en el SMATA a través de la Tendencia de Avanzada Mecánica (TAM). En MBA, en la figura de Charles Grossi, estuvo inserto desde 1968 hasta su despido en noviembre de $1973 .{ }^{20}$ Aun así, posterior a la expulsión, el PST siguió actuando en la fábrica, pero con una influencia menor. Un delegado de ese entonces recuerda que Charles Grossi se acercó a la huelga de 1975 para solidarizarse con los trabajadores. ${ }^{21}$

En el artículo de balance de su periódico Avanzada Socialista, titulado "Mercedes marchó hasta el triunfo", el PST sostuvo, sin mención alguna al secuestro llevado a cabo por Montoneros, que "una importante movilización de los trabajadores de Mercedes Benz a la casa central de la empresa en la Capital"22 fue lo que posibilitó el éxito, sumándole, posteriormente, como factores relevantes, la solidaridad obrera y la organización interna.

Otra organización que fue parte de la lucha sindical en MBA fue el $\mathrm{PB}$, penetrando a finales de 1974 producto de la incorporación a la fábrica de un militante -proveniente del ámbito universitario- que llegó a ser delegado de su sección durante el enfrentamiento.

Por otro lado, el PCR y el GOR tuvieron cierta presencia en la empresa durante el conflicto, aunque definitivamente menor que la de la JTP, el PRT, el PC y el PST.

El PCR tuvo una mirada un tanto ambigua del paro de labores, lo que quizá se deba a su apoyo en aquel momento al gobierno nacional. En el artículo "Se acabó la paciencia" sostuvieron que cuando se acercaron a la fábrica a preguntar sobre la huelga, "un compañero" afirmó: "Acá

19. "El SMATA de las bases", Nuestra Palabra, 5 de noviembre de 1975.

20. Grossi, según él relata en Avanzada Socialista del 29 de noviembre de 1973, ingresó en 1955 a la corriente que luego derivaría en el PST. Su militancia estuvo siempre centrada en la UOM y el SMATA. Dirigió la toma de AVAN en 1964 que terminó en un triunfo por lo que luego fue expulsado del sindicato por Rucci. También trabajó en General Motors y fue delegado en Mercedes Benz (Charles Grossi, "Relatos de un luchador: Charles Grossi", Avanzada Socialista, 29 de noviembre de 1973). Un entrevistado recuerda que luego de ser despedido de MBA continuó trabajando en la metalúrgica Santa Rosa, también de La Matanza (entrevista realizada a "Federico" el 19 de septiembre de 2015). Fue desaparecido por la última dictadura militar en agosto de 1977.

21. Entrevista realizada a "Federico" el 19 de septiembre de 2015.

22. "Mercedes marchó hasta el triunfo", Avanzada Socialista, 31 de octubre de 1975. 
hay varias cosas que huelen feo -comentaba un compañero- porque este conflicto se podría solucionar rápida y fácilmente pero la empresa, Rodríguez y los del enjambre prorruso que actúa en planta no hacen otra cosa que echar leña al fuego". ${ }^{23}$ En este sentido, a lo largo de la mencionada nota del periódico Nueva Hora, afirmaron que la cúpula sindical, la empresa y "el enjambre prorruso" buscaban radicalizar el enfrentamiento. A lo que agregaron que estos últimos "pretenden utilizar los justos reclamos de los trabajadores para echarle fardo al Gobierno". Vale decir que su intención, durante la huelga, fue intentar "arribar a una justa solución al problema". ${ }^{24}$

De la lectura de las publicaciones de las organizaciones que actuaron en la refriega se evidencia que uno de los principales debates que circuló entre ellas (exceptuando el PC) se dio en relación a la operación guerrillera llevada a cabo por Montoneros.

En el número 10 de Evita Montonera, bajo el título "El flanco débil del enemigo", se conceptualizó el porqué de la eficacia de este tipo de operaciones. Allí se sostuvo que si bien los "monopolistas" -en tanto clase social- son el fundamento del poder, si se los ataca de esta manera se puede obtener su rendición individual. En este sentido, asaltos a la propiedad o sobre individuos representantes del capital -que pueden no llegar a ser un secuestro-, permiten romper la "santa alianza" entre empresarios, burocracia y gobierno, obteniendo así una negociación directa y la posibilidad del éxito. También agregan que este tipo de actividad"acompaña el desarrollo organizativo de las bases". ${ }^{25}$

Como se mencionó, para el PRT "el secuestro de un integrante del directorio de la empresa, llevado a cabo por la organización hermana Montoneros, vino a robustecer y dar nuevas perspectivas al combate proletario". ${ }^{26}$ De esta manera le asigna un lugar a la detención en la victoria obrera, pero sin reducir el triunfo al mismo.

El PST no mencionó al rapto en su artículo de balance, pero sí le dedicó en el número inmediatamente posterior (del 8 de noviembre de 1975) una nota de opinión firmada por Ernesto González titulada "La acción guerrillera en Mercedes Benz". El dirigente afirmaba:

La semana pasada decíamos que la vanguardia obrera y sectores importantes del conjunto de la clase trabajadora comenzaban a expresarse públicamente contra los actos de terrorismo de la guerrilla. Ahora, no podemos dejar de señalar

23. "Se acabó la paciencia", Nueva Hora, 29 de octubre al 4 de noviembre de 1975, p. 5. 24. İdem.

25. "El flanco débil del enemigo", Evita Montonera, noviembre de 1975, p. 23.

26. “Triunfo obrero en Mercedes Benz”, El Combatiente, 5 de noviembre de 1975, p. 15. 
que también hay algunas acciones guerrilleras que son vistas con simpatía por la vanguardia. Este es el caso, por ejemplo, de los compañeros de Mercedes Benz, que acaban de triunfar en un conflicto memorable. ${ }^{27}$

Para luego preguntarse si los guerrilleros

\begin{abstract}
han abandonado por completo su politica terrorista de matar policías, militares, empresarios, dirigentes sindicales y hasta conscriptos (como en el caso de Formosa). Esta es la verdadera discusión y la pregunta clave que deben contestar los partidarios del guerrillerismo. ¿Han abandonado totalmente esta politica ajena a las masas para dedicarse solo a acciones ligadas a ellas y a sus luchas, o por el contrario, su acciones sigue siendo, esencialmente, del primer tipo? ${ }^{28}$
\end{abstract}

De esta manera el artículo citado de Avanzada Socialista deja entrever que para ellos el movimiento obrero apoyó el secuestro y que este tipo de operaciones, a diferencia de otras actividades armadas, estarían vinculadas a las masas y a sus luchas, pero serían solamente una ínfima cantidad respecto de sus otros "actos de terrorismo".

Por último, el PCR sostuvo en un artículo escrito posterior a la victoria obrera, que "algunos compañeros [...] nos manifestaron que repudiaban el secuestro del directivo de la Mercedes y el terrorismo que pretendía confundir la lucha". Para luego agregar que el triunfo pretendió "ser instrumentado por el terrorismo golpista". ${ }^{29}$

\title{
Balance del conflicto y la acción guerrillera
}

Es necesario subrayar el momento en que se desenvuelve el enfrentamiento: octubre de 1975 es tres meses después de las huelgas generales con epicentro en Buenos Aires conocidas popularmente como las jornadas contra el "Rodrigazo". Pero se sitúa en un momento en que la movilización disminuye, la represión hacia el activismo fabril aumenta y las disputas laborales se vuelven más prolongadas y agudas.

En relación a los pormenores del paro, el primer dato a mencionar son sus objetivos. Que el enfrentamiento haya sido para reclamar el fin de la intervención y exigir el llamado a elecciones para la comisión in-

27. Ernesto González, "La acción guerrillera en Mercedes Benz", Avanzada Socialista, 8 de noviembre de 1975 .

28. Ibídem.

29. "Gran triunfo", Nueva Hora, del 5 al 11 de noviembre de 1975, p. 5. 
terna expresa cierto grado de politización. Los trabajadores de Mercedes Benz lucharon para que en el parlamento obrero -según la expresión utilizada en La anomalía argentina (Gilly, 1990)- de González Catán puedan tener representantes elegidos por ellos y que éstos tengan más contacto con las bases. Si se le suma el hecho de que fue dirigida por organizaciones políticas del peronismo combativo y el marxismo y se le adiciona la importancia política y sindical que tuvieron ese tipo de organismos gremiales en dicho año (fundamentales en la movilización contra el Rodrigazo) nos demuestra cierta politización de los trabajadores de la terminal automotriz.

No es menor, tampoco, que quienes tuvieron la iniciativa e iniciaron el conflicto fueron los trabajadores y cuando la empresa intentó recobrarla con los 117 despidos lograron una nueva ofensiva que les brindó la victoria.

Otro dato de relevancia es la masividad que tuvo la medida de fuerza desde su inicio hasta su fin, así como la unidad de los obreros (como lo expresó la consigna "los 4.000 adentro, o los 4.000 afuera") y la participación de los empleados administrativos de la planta en el enfrentamiento. También es sustancial que el triunfo fue vivido como propio por los operarios, lo que se evidencia en la vuelta olimpica que dieron luego de su finalización y en el cambio en la correlación de fuerzas entre obreros y gerencia luego de octubre de 1975.

En relación al rapto de Metz, la reconstrucción de los hechos evidencia que estuvo articulado al dinamismo propio del conflicto, dado que se enmarcó en la ofensiva obrera posterior a los despidos. De hecho, las principales movilizaciones acontecieron a los pocos días del secuestro. Tampoco se puede dejar de lado que quien la ejecutó fue la principal organización política inserta en la fábrica.

La mayoría de las fuentes, ya sean entrevistas o datos secundarios, coinciden en que la detención del ejecutivo fortaleció la posición de los trabajadores en la huelga o, al menos, no restó fuerza. Por ejemplo, "Juan" afirmó:

A ver, todos fuimos conscientes de que el conflicto se resolvió favorablemente porque el secuestro de Metz ayudó. Ahora, en realidad, no sabemos, por ahí el conflicto se podía llegar a prolongar porque, bueno, en realidad habia mucha fuerza y había una inserción social muy grande con Cañuelas y con González Catán, y había apoyo de otras fábricas. ${ }^{30}$

30. Entrevista realizada a "Juan" el 20 de julio de 2015. 
Más categórico en la evaluación de la acción guerrillera es "Federico", activista en la fábrica desde 1967 autodefinido como de izquierda,

$\mathrm{Y}$ en ese momento secuestran a Metz y las negociaciones cambiaron, nos favoreció el secuestro. Porque agilizó todo, el tiempo te va desgastando y eso permite que el sindicato haga su trabajo tratando de agarrar a quienes no estaban tan firmes en sus convicciones y que tuvieran familia. ${ }^{31}$

El informe Tomuschat también coincide en la caracterización:

A causa de ello [el secuestro], pero también a causa de varias grandes manifestaciones frente a la central de MBA en Buenos Aires y de una manifestación el 27 de octubre de 1975 frente al Ministerio de Trabajo, la dirección de la empresa se vio obligada a ceder. (Tomuschat, 2003)

Aunque la cúpula del SMATA estuvo terminantemente en contra del paro, llegó a la conclusión de que el secuestro sirvió como "carta de negociación":

Desde el punto de vista gremial, fue una huelga sin objetivos, es decir, fue una acción provocativa arteramente amañada por agitadores profesionales con el único fin de usar a los trabajadores como "cobayos" de una experiencia sediciosa. El apoyo prestado al conflicto por una organización extremista, el posterior "secuestro" de un directivo empresario como carta de negociación y la "solución" pactada como desenlace del diferendo, constituyen la mejor prueba de ello. ${ }^{32}$

La gran mayoría de los datos recolectados se acercan a la idea de que el secuestro -en mayor o menor medida-favoreció a los huelguistas en el enfrentamiento. Lo que coincide con el derrotero de la disputa: el 24 se ejecuta la detención, el 27 la empresa empieza a ceder, el 28 se hace una gran marcha hacia el Ministerio de Trabajo y el 29 se realiza una masiva movilización a la casa central. Allí, en la negociación entre el "grupo de los 9" y la gerencia, los obreros obtienen todas sus reivindicaciones y la medida de fuerza termina en victoria.

La evidencia empírica presentada permitiría confirmar la hipótesis

31. Entrevista realizada a "Federico" el 19 de septiembre de 2015.

32. José Rodríguez, "SMATA: A la opinión pública del país", Clarín, 6 de noviembre de 1975, p. 16. 
planteada al inicio del artículo: la operación de Montoneros fortaleció la posición de los trabajadores en la contienda.

Resta ver cuál fue el apoyo que suscitó la acción por parte de los obreros. Si bien conseguir el dato con precisión escapa a las posibilidades de la investigación, con la triangulación de diversas fuentes se puede obtener una estimación.

La mayoria de los datos secundarios coinciden en el apoyo que recibió el rapto por parte de un sector movilizado de los trabajadores de la empresa. Que un dirigente del PST, una organización opuesta a este tipo de actividad, haya afirmado en un artículo exclusivamente abocado a la operación guerrillera que la vanguardia de MBA vio con simpatía el secuestro indicaría esta cuestión. ${ }^{33}$

Una fuente secundaria que dio una versión distinta fue el periódico Nueva Hora, el cual sostuvo que "algunos compañeros" condenaban "el terrorismo". Pero definitivamente no hay evidencia para creer que fue una visión mayoritaria en la fábrica, más cuando esos "algunos compañeros" utilizaban una terminología similar a la de la línea editorial del PCR, como el poco usual "enjambre prorruso". ${ }^{34}$

Por otro lado, las entrevistas a ex trabajadores realizadas en la actualidad permiten complejizar más la cuestión. Un dispositivo como una entrevista semiestructurada genera que en los distintos discursos de los obreros se entremezcle pasado y presente, las opiniones actuales con las de hace cuarenta años. Por ejemplo, "Juan", militante de PB en ese momento, considera:

En realidad yo creo que la opinión estaba un poco dividida. Después cuando lo charlamos con muchos compañeros dijeron: "no, porque estuvo mal, qué se yo". Sí, en realidad si uno se lo poner a ver es querer reemplazar una fuerza que no tiene. Ahora después si uno piensa que era un tipo que fue criminal de guerra, no sé si estuvo tan mal, porque era un nazi. ${ }^{35}$

\section{"Federico" sostuvo:}

Nosotros formábamos parte de un comité de lucha y veíamos que estaba bien porque ayudaba a lograr nuestros objetivos.

33. No era frecuente que el partido de Nahuel Moreno afirme que los trabajadores apoyaban el accionar armado. Por ejemplo, Santella (2009) relata cómo en un conflicto en Villa Constitución sucedido meses antes, el PST, en sus publicaciones escritas, afirmó que los obreros metalúrgicos repudiaban la ejecución por parte de Montoneros de un subjefe de policia. Rechazo que, según relata el investigador, no fue tal.

34. "Se acabó la paciencia", Nueva Hora, 29 de octubre al 4 de noviembre de 1975, p. 5. 35. Entrevista realizada a "Juan" el 20 de julio de 2015. 


\begin{abstract}
Ahora en el conjunto de la gente, no quiero decir que sí, pero yo creo que al ver los resultados, menos los que eran abiertamente partidarios del sindicato, estaban de acuerdo, o al menos lo vieron con simpatía. En ese momento eran muchos los secuestros que se daban a los empresarios. ${ }^{36}$
\end{abstract}

Por su parte, "Pedro", militante del PRT, opina que "el trabajador como yo lo aplaudimos. El hecho no está criticable. Lo que está criticado es el momento, esa oportunidad, el momento no era el propicio, tenían que haber elegido otro momento". ${ }^{37}$

El testimonio de "Juan" permite pensar que dentro de los 4.000 operarios existieron posiciones divergentes. Pero no da muchas pistas sobre cómo era cada grupo.

Quizá ayuda a precisar esta información el testimonio de "Federico". El comité de lucha era un espacio organizativo que reunía al activismo más movilizado de la fábrica, por lo que sus palabras incentivan a pensar que el sector que apoyó la detención no estuvo caracterizado por su falta de participación sindical. Pero, para "Federico", la simpatía no se redujo a ese espacio específico, sino que tuvo un alcance mayor hacia "el conjunto de la gente".

Un dato sugestivo de la opinión de "Federico" reside en que él se oponía al peronismo como movimiento ("Volvió Perón [...] y de ahí salió una lucha más profunda de lo que era la idea del peronismo y de lo que éramos nosotros"), ${ }^{38}$ pero aun así consideró que la acción de Montoneros "servía para la causa". ${ }^{39}$

Por último, si bien "Pedro" se opuso al momento en que se llevó a cabo el secuestro ("El hecho no está criticable. Lo que está criticado es el momento"), sus palabras abonan la idea de que un sector vio con simpatía la maniobra guerrillera ("el trabajador como yo lo aplaudimos").

En resumen, aunque no se puede obtener con exactitud el grado de apoyo que suscitó el secuestro de un alto ejecutivo, la triangulación de las múltiples fuentes nos acerca a pensar que dentro de los 4.000 operarios de la terminal alemana existieron visiones divergentes. Y posiblemente el sector que apoyó la operación guerrillera era uno de los más movilizados de la fábrica. Incluso, habria indicios de que la aprobación no se redujo solamente a ese grupo específico.

36. Entrevista realizada a "Federico" el 19 de septiembre de 2015.

37. Entrevista realizada a "Pedro" el 15 de abril de 2013.

38. Entrevista realizada a "Federico" el 19 de septiembre de 2015.

39. Ídem. 


\section{Conclusiones}

En la primera parte de la década del 70 en Argentina fueron numerosas, de diverso tipo y con resultados disimiles las intervenciones armadas de las OPM durante los enfrentamientos obrero-patronales. De esta manera, la relación entre acciones guerrilleras y conflictos obreros es un aspecto no menor del vínculo entre el movimiento obrero y la violencia política.

Un debate posible es la manera de interpretar este fenómeno social, es decir, ver desde qué postura partir para dar cuenta del problema de una forma que considere sus matices y tensiones.

El gigante invertebrado: los sindicatos en el gobierno, Argentina 19731976 (Torre, 2004), cuya primera aparición data de 1983, e Insurgencia obrera en la Argentina 1969-1976 (Werner y Aguirre, 2009) son libros que trataron de manera aguda algunos elementos de la relación entre el movimiento obrero y la violencia política. Más allá de tratarse de tan solo dos ejemplos dentro de un cuerpo bibliográfico mucho más vasto, la riqueza de sus análisis, su mirada de largo alcance y la amplia difusión de sus planteamientos invitan a reflexionar sobre ellos. El interrogante que surge es: ¿desde qué perspectiva analizaron los diversos aspectos que hacen al vinculo mencionado? No se trata, aclaramos, de realizar un proceso inductivo a partir de un caso, sino, más bien, ver desde qué enfoque se investiga la temática.

Para el primer autor existen dos lógicas distintas, la de los conflictos sociales y la de la violencia, cancelando las posibles relaciones entre ambas. Por ejemplo, sostiene: "Creemos que durante ese periodo es posible hablar de conflictos sociales, en otras palabras, que quienes se propusieron llevar al país a una situación en la que la lógica de la violencia aboliera la lógica de los conflictos sociales no lo lograron" (Torre, 2004: 132).

Esta afirmación de Torre permite preguntarnos: partir de tan radical distinción entre ambas "lógicas", en donde la violencia es externa al conflicto y es impuesta por sujetos ajenos a él, ¿es la mejor manera para comprender la dimensión violenta que tuvieron algunos conflictos sociales?

Un enfoque distinto para pensar la relación entre el movimiento obrero y la violencia política en la primera parte de la década del 70 en Argentina quizá es posible de ser construido desde la sugerencia de Adolfo Sánchez Vázquez, para quien "la lucha de clases se desarrolla históricamente con un coeficiente mayor o menor de violencia" (Sánchez Vázquez, 2003: 434). En este sentido, ¿no sería más provechoso considerar que la propia "lógica" del enfrentamiento puede llevar a que cuando éste se agudiza adquiera una forma violenta? 
Por su parte, el libro Insurgencia obrera en la Argentina ,1969-1976 considera que la lucha de clases en su propio desarrollo puede tornarse violenta:

Cuando se habla del período abierto por la eclosión cordobesa, todas las visiones tienden a coincidir en que en aquellos años el enfrentamiento entre civiles, la división en bandos de la sociedad y la dura lucha de clases constituían un cuadro general de violencia política. (Werner y Aguirre, 2009: 36).

Pero aíslan la actividad de los agrupamientos guerrilleros de la lucha de clases. De esta manera los autores consideran, por ejemplo, que "la acción de las organizaciones armadas, centralmente Montoneros y ERP, era también un elemento presente en la política nacional. Pero el proceso más dinámico se dará en el terreno de la lucha de clases" (Werner y Aguirre, 2009: 34).

Más que hablar de una absoluta ajenidad entre lucha armada y lucha de clases, ¿no ayudaria, para dar cuenta de los enfrentamientos sociales sucedidos en la primera parte de la década del 70 en Argentina, pensar el accionar militar de las OPM como una de las diversas formas que adquirió la lucha de clases cuando ésta tomó algún grado de violencia? Quizá ahondar en esta última cuestión evitaría tanto reducir la lucha de clases a la actividad guerrillera como excluir a las operaciones armadas de las OPM de ella.

Exponer una huelga como la de MBA induce a reflexionar sobre estos interrogantes planteados. Al señalar, a contracorriente de las visiones más difundidas, que la intervención armada durante conflictos obreros no necesariamente funcionó como un impedimento a la lucha de los trabajadores argentinos en la década del 70, se puede plantear el debate sobre las diferencias que existieron entre los casos en que operó como obstáculo y en los que no fue así. En este sentido finalizamos preguntándonos: ¿qué es lo que hizo que en Mercedes Benz la lucha guerrillera abone a la movilización obrera? ¿Por qué se dio de esa manera en este caso y en otros la actividad armada complicó la posición de los trabajadores en lucha?

\section{Bibliografia}

Balvé, Beba C. et al. (2007), Lucha de calles, lucha de clases, Buenos Aires: RyR.

Basualdo, Victoria, y Federico Lorenz (2012), "Los trabajadores industriales argentinos en la primera mitad de la década del 70: Propuestas para una agenda de investigación a partir del análisis comparativo de casos", 
Páginas. Revista Digital de la Escuela de Historia, año IV, n 6, Rosario, pp.123-157.

Brennan, James (1996), El Cordobazo: las guerras obreras en Córdoba, 1955-1976, Buenos Aires: Sudamericana.

Cotarelo, María Celia, y Fabián Fernández (1998), Huelga general con movilización de masas. Argentina, junio y julio de 1975, Buenos Aires: PIMSA.

Gilly, Adolfo (1990), "La anomalía argentina (Estado, corporaciones y trabajadores)", en Pablo González Casanova (comp.), El Estado en América Latina: teoría y práctica, México: Siglo XXI, pp. 187-213.

Izaguirre, Inés (2009), Lucha de clases, guerra civil y genocidio en la Argentina, 1973-1983: Antecedentes, desarrollo, complicidades, Buenos Aires: Eudeba.

James, Daniel (1990), Resistencia e integración. El peronismo y la clase trabajadora Argentina, 1946-1976, Buenos Aires: Sudamericana.

Kroll, Hans Gundermann (2008), "El método de los estudios de caso", en M.L. Tarrés (coord.), Observar, escuchar y comprender, México: El Colegio de México, pp. 278-317.

Löbbe, Héctor (2006), La guerrilla fabril. Clase obrera e izquierda en la coordinadora de zona norte del Gran Buenos Aires (1975-1976), Buenos Aires: RyR.

Marín, Juan Carlos (2007), Los hechos armados. La acumulación primitiva del genocidio. Argentina, 1973-1976, Buenos Aires: La Rosa Blindada.

Sánchez Vázquez, Adolfo (2003), Filosofía de la praxis, México: Siglo XXI.

Santella, Agustin (2009), "Las guerras obreras en la Argentina. Villa Constitución, 1973-1975”, en Inés Izaguirre (comp.), ob. cit., pp. 286-308.

Tomuschat, Christian (2003), "Mercedes Benz Argentina durante la dictadura militar (1976-1983)", Informe, p. 36.

Torre, Juan Carlos (2004), El gigante invertebrado. Los sindicatos en el gobierno. Argentina, 1973-1976, Buenos Aires: Siglo XXI.

Weber, Gabriela (2005), La conexión alemana. El lavado de dinero nazi en Argentina, Buenos Aires: Edhasa.

Werner, Ruth, y Facundo Aguirre (2009), Insurgencia obrera en Argentina, 1969-1976. Clasismo, coordinadoras interfabriles y estrategias de izquierda, Buenos Aires: Ediciones IPS.

Titulo: Labor conflict and guerrilla action. The strike in Mercedes Benz Argentina in 1975 and the kidnapping of a nazi

Resumen: El presente artículo trata sobre la relación entre el movimiento obrero y la violencia política, específicamente la vinculación entre conflictos obreros y acciones guerrilleras. Para ello, se toma como caso la huelga sucedida en Mercedes Benz Argentina (MBA) en octubre de 1975 durante la cual Montoneros secuestró al gerente de producción como forma de apoyo a los trabajadores. 
Palabras clave: conflicto obrero - violencia politica - industria automotriz acción sindical

Abstract: This articule is about the relation between workers movement and political violence, specifically the bonding between labor conflict and guerrilla action. To discuss about that we take the case of the strike that hapened on october of 1975 in Mercedes Benz factory located in Argentina, during the strike Montoneros kidnapped the production manager.

Keywords: labor conflict - political violence - automotive industry - trade union action

Recepción: 12 de mayo de 2016. Aprobación: 28 de agosto de 2016 . 